\title{
Prevalence of R Factors in Pseudonomas aeruginosa
}

\author{
By MEGUMI KONO AND KOJI O'HARA \\ Department of Microbiology, Tokyo College of Pharmacy, \\ I-I0-I9, Ueno-sakuragi, Taito-ku, Tokyo I Io, Japan
}

(Received 4 September 1974; revised 22 March 1975)

\section{INTRODUCTION}

There are many reports of R factors in Pseudomonas aeruginosa (Roe, Jones \& Lowbury, I97I; Witchitz \& Chabbert, I97I; Bryan, Van den Elzen \& Tseng, I972; Grinsted et al. I972; Olsen \& Shipley, 1973; Iyobe et al. 1974; Van Rensburg \& de Kock, 1974) but there has been little work on the prevalence of $\mathrm{R}$ factors in clinical isolates of $P$. aeruginosa (see Holloway \& Richmond, I973). We have surveyed the drug resistances of 89 distinct strains of $P$. aeruginosa isolated from patients suffering from urinary tract infections and have found that $\mathrm{IO}(\mathrm{II} \cdot 2 \%)$ of the isolates transfer one or more of their resistance determinants to drug-sensitive recipients.

\section{METHODS}

Bacterial strains. Eighty-nine strains of $P$. aeruginosa (designated K-Ps) were isolated from patients with urinary tract infections, and the sensitivity of these strains to a series of antibiotics was determined by an agar dilution method at $37^{\circ} \mathrm{C}$. Strains were considered to be resistant when the minimum inhibitory concentration (m.i.c.) exceeded the following $(\mu \mathrm{g} /$ $\mathrm{ml}$ ): chloramphenicol, 200; tetracycline, 200; streptomycin, 400; sulphonamide (sodium sulphisomidine), 6400; kanamycin, 400; gentamicin, $3 \cdot 13$; carbenicillin, 400.

A rifampicin-resistant mutant of strain K-PS47 was selected by picking a colony that grew on nutrient agar (Eiken, Tokyo) containing $100 \mu \mathrm{g}$ rifampicin $/ \mathrm{ml}$. It is designated K-PS47RFP.

Serological typing. The method of Homma (1974) was used.

Transfer of drug resistance. Transfer was done by mixed cultivation of donor and recipient, either in broth or on agar. For both methods, stationary-phase cultures of donor and recipient that had been grown in brain-heart infusion broth (BHI; Difco) were inoculated to a density of $5 \times 10^{8}$ bacteria $/ \mathrm{ml}$ in fresh BHI supplemented with $0.4 \%$ (w/v) $\mathrm{KNO}_{3}$ and incubated at $37^{\circ} \mathrm{C}$ with shaking to give exponentially-growing cultures of about $2 \times 10^{9}$ bacteria $/ \mathrm{ml}$.

For the broth method, donor $(0.3 \mathrm{ml})$ and recipient $(\mathrm{I} \cdot 5 \mathrm{ml})$ of these exponentially-growing cultures were mixed and incubated for about $2 \mathrm{~h}$ at $37^{\circ} \mathrm{C}$ with gentle agitating on a shaker (Monoshin, Taiyo Kagaku Kogyo, Tokyo). Mixed culture (0.I ml) was spread on to the nutrient agar containing the selective agent; culture containing donor alone $(0.1 \mathrm{ml})$ was also spread on to a similar plate to count the number of donors used. The plates were incubated for $\mathrm{I} 8 \mathrm{~h}$ at $37^{\circ} \mathrm{C}$ and colonies were counted. For selection for sulphonamide resistance, Mueller Hinton medium (Eiken, Tokyo) was used instead of nutrient agar.

For the agar method, donor $(0.02 \mathrm{ml})$ and recipient $(0 . \mathrm{I} \mathrm{ml})$ from the exponentially-growing cultures were mixed and spread on nutrient agar. After incubation for $\mathrm{I} 8 \mathrm{~h}$ at $37^{\circ} \mathrm{C}$, the bacteria from the plates were harvested, resuspended in $20 \mathrm{ml}$ distilled water and $0.2 \mathrm{ml}$ 
was spread on the selective agar. The culture without recipient was also spread on to the nutrient agar containing the selective agent, to determine the number of donors present. Colonies that grew after $\mathrm{I} 8 \mathrm{~h}$ incubation of the plates at $37^{\circ} \mathrm{C}$ were counted.

Transfer frequency is defined as the number of $\mathbf{R}$ factor-containing recipients divided by the number of donor cells present after each mating. The concentrations of drugs used in the selective agar plates were as follows $(\mu \mathrm{g} / \mathrm{ml})$ : rifampicin, I00; chloramphenicol, 800; streptomycin, 500; kanamycin, 500; gentamicin, 6.25; carbenicillin, 400; sulphonamide, 6400 .

\section{RESULTS AND DISCUSSION}

Eighty $(90 \%)$ of the strains tested were resistant to one or more of the antibiotics used and ten (II \%) of these were found to transfer at least one resistance determinant to K-PS47RFP (Table I). The serotype of the conjugants was checked and found to be that of the recipient (serotype 3). The m.i.c. of the conjugants were similar to those of the donor so that it is extremely unlikely that the results can be explained on the basis of mutation of the recipient, particularly when more than one resistance determinant is transferred. The frequency of transfer varied from $10^{-6}$ to $10^{-8}$, but with no obvious correlation with the type of $\mathrm{R}$ factor transferred.

For seven of the donors there was evidence of co-transfer of two or more resistance determinants but in the other three only one of the two or three resistances were transferred.

With kanamycin as the selective agent, all five drug-resistance determinants were transferred from strain K-PSI02 (Table I) but it was found in a separate experiment that with chloramphenicol as selective agent only four of them were transferred. The conjugant was sensitive to kanamycin. An experiment was designed to test whether or not there was segregation of the genes for resistance to various antibiotics in strain K-PSI02.

All five antibiotics were used separately to select conjugants in a transfer experiment in which K-PSI02 was the donor and K-PS47RFP the recipient. Twenty-seven colonies from each selection system were purified and then inoculated in cooked meat medium (Eiken, Tokyo). The colonies were stored at room temperature and the sensitivity of the stock culture was determined for various concentrations of the antibiotic in the agar, after 2 days, 2 months and 18 months.

Of the 27 purified cultures that were tetracycline-resistant, two were sensitive to kanamycin after 2 days' incubation. Similarly, of the purified cultures that were sulphonamide-, chloramphenicol- or streptomycin-resistant (27 of each), five, five and two were sensitive to kanamycin after 2 days' incubation (data not presented). Segregation and loss of drugresistance determinants after 2 months' incubation are shown in Table 2 . The results can be interpreted as showing that loss of the $\mathrm{R}$ factor is occurring and that the probability of loss varies according to the original selective agent. Thus, there was no loss of $\mathbf{R}$ factor when tetracycline or sulphonamide was the selective agent but there was some loss when chloramphenicol or streptomycin was used and considerable loss with kanamycin. Segregation may have occurred at some stage, and there was a loss of either the kanamycin determinant or the four-antibiotic-resistance determinant, or both, on prolonged incubation.

The segregation of the five-antibiotic-resistance determinant tends to depend on the type of selective agent. When tetracycline, sulphonamide, chloramphenicol or streptomycin was used as selective agent, the conjugants tended to lose the kanamycin-resistance determinant, leaving the four-antibiotic-resistance determinant in the stock cultures. However, loss of the four-antibiotic-resistance determinant was observed in the conjugants obtained by kanamycin selection, leaving a kanamycin-resistance-determinant which retained trans- 
Table I. Transfer of drug-resistance determinants in P. aeruginosa

$\begin{array}{lcccc}\text { Donor } & \text { Resistant to: } & \begin{array}{c}\text { Conjugants } \\ \text { selected } \\ \text { on: }\end{array} & \begin{array}{c}\text { Phenotype of } \\ \text { conjugant } \\ \text { resistant to: }\end{array} & \begin{array}{c}\text { Frequency of } \\ \text { transfer* }\end{array} \\ \text { K-PS28 } & \text { CK } & \text { C } & \text { C } & 1 \times 10^{-6}(b) \\ \text { K-PS84 } & \text { KG } & \text { G } & \text { G } & 2 \times 10^{-8}(a) \\ \text { K-PS97 } & \text { SKSu } & \text { K } & \text { K } & 4 \times 10^{-7}(b) \\ \text { K-PSI00 } & \text { CSu } & \text { C } & \text { CSu } & 1 \times 10^{-8}(b) \\ \text { K-PSI08 } & \text { SuCb } & \text { Cb } & \text { SuCb } & 2 \times 10^{-7}(b) \\ \text { K-PS94 } & \text { CSK } & \text { K } & \text { SK } & 2 \times 10^{-8}(a) \\ \text { K-PS79 } & \text { CSSu } & \text { S } & \text { CSSu } & 6 \times 10^{-7}(b) \\ \text { K-PS60 } & \text { TCSSu } & \text { C } & \text { TCSSu } & 5 \times 10^{-8}(b) \\ \text { K-PS6I } & \text { TCSSu } & \text { C } & \text { TCSSu } & 4 \times 10^{-6}(b) \\ \text { K-PS102 } & \text { TCSSuK } & \text { K } & \text { TCSSuK } & 1 \times 10^{-6}(b)\end{array}$

Abbreviations: C, chloramphenicol; G, gentamicin; K, kanamycin: $\mathrm{Cb}$, carbenicillin; Su, sulphonamide; S, streptomycin; T, tetracycline.

* (a) Agar method; (b) broth method.

Table 2. Segregation and loss of drug-resistance determinants

$\begin{array}{ccccc}\begin{array}{c}\text { Original } \\ \text { selective } \\ \text { drug }\end{array} & \text { TCSSu } & \text { TCSSuK } & \text { K only } & \begin{array}{c}\text { No. of } \\ \text { colonies } \\ \text { sensitive }\end{array} \\ \text { T } & 27 & 0 & 0 & 0 \\ \text { Su } & \text { I6 TCSSuK } \\ \text { C } & 22 & 1 \text { I } & 0 & 0 \\ \text { S } & 13 & \text { I } & 0 & 4 \\ \text { K } & 0 & \text { I } & 0 & \text { I3 } \\ & & 4 & 2 & 2 \text { I }\end{array}$

Results were determined after 18 months' incubation. For'abbreviations, see Table $\mathbf{I}$.

Table 3. Segregation and loss of drug-resistance determinants

\begin{tabular}{|c|c|c|c|c|}
\hline \multirow{2}{*}{$\begin{array}{l}\text { Original } \\
\text { selective } \\
\text { drug }\end{array}$} & \multicolumn{3}{|c|}{ No. of colonies resistant to: } & \multirow{2}{*}{$\begin{array}{c}\text { No. of } \\
\text { colonies } \\
\text { sensitive } \\
\text { to TCSSuK }\end{array}$} \\
\hline & TCSSu & TCSSuK & $\mathrm{K}$ only & \\
\hline $\mathrm{T}$ & 26 & 0 & 0 & I \\
\hline $\mathrm{Su}$ & 26 & 0 & 0 & $\mathbf{I}$ \\
\hline C & 13 & 0 & 0 & 14 \\
\hline $\mathbf{S}$ & I I & $\mathbf{I}$ & 0 & 15 \\
\hline $\mathbf{K}$ & 0 & I & 5 & $2 I$ \\
\hline
\end{tabular}

Results were determined after 2 months' incubation. For abbreviations, see Table I.

ferability to a new recipient. These segregants gradually decreased in the stock cultures after a further incubation for I8 months (Table 3).

We thank Dr T. Nishimura and Dr Y. Kawada, Department of Urology, Faculty of Medicine, University of Gifu, for providing the bacteria, and Professor J. Y. Homma, Institute for Medical Science, University of Tokyo, who helped with the serological typing of $P$. aeruginosa. 


\section{REFERENCES}

Bryan, L. E., VAN Den Elzen, H. M. \& Tseng, J. T. (1972). Transferable drug resistance in Pseudomonas aeruginosa. Antimicrobial Agents and Chemotherapy r, 22- 29.

Grinsted, J., Saunders, J. R., Ingram, L. C., Syykes, R. B. \& Richmond, M. H. (1972). Properties of an $\mathrm{R}$ factor which originated in Pseudomonas aeruginosa 1822. Journal of Bacteriology 1ro, 529-537.

Holloway, B. W. \& Richmond, M. H. (1973). R-factors used for genetic studies in strains of Pseudomonas aeruginosa and their origin. Genetical Research 2r, 103-105.

Homma, J. Y. (1974). Serological typing of Pseudomonas aeruginosa and several points to be considered. Japanese Journal of Experimental Medicine 44, I-I 2.

Iyobe, S., Hasuda, K., Fuse, I. \& Mitsuhashi, S. (1974). Demonstration of R factors from Pseudomonas aeruginosa. Antimicrobial Agents and Chemotherapy 5, 547-552.

OlSEN, R. H. \& SHIPLEY, P. (I973). Host range and properties of the Pseudomonas aeruginosa R factor RI 822. Journal of Bacteriology $\mathrm{Ir}_{3}, 772-780$.

Roe, E., Jones, R. J. \& Lowbury, E. J. L. (1971). Transfer of antibiotic resistance between Pseudomonas aeruginosa, Escherichia coli, and other Gram-negative bacilli in burns. Lancet, i, $769 \mathrm{I}-7694$.

VAN Rensburg, A. J. \& DE Kock, M. J. (1974). A new R factor from Pseudomonas aeruginosa. Journal of General Microbiology 82, 207-208.

Witchitz, J. L. \& ChABbert, Y. A. (I971). Resistance transferable à la gentamicin. I. Expression du caractere de resistance. Annales de l'Institut Pasteur 121, 733-742. 